\title{
LOS MIEMBROS FEMENINOS DE LA TERCERA ORDEN FRANCISCANA EN ANDALUCÍA A FINALES DE LA EDAD MEDIA
}

\author{
POR \\ SiLVIA MARÍA PÉREZ GONZÁLEZ ${ }^{1}$ \\ Universidad Pablo de Olavide de Sevilla \\ Y \\ JOSÉ SÁNCHEZ HERRERO² \\ Universidad de Sevilla
}

\section{RESUMEN}

El presente trabajo tiene como objeto de estudio a los miembros femeninos de la Tercera Orden franciscana que vivieron en Andalucía a finales de la Edad Media. En la primera parte tratamos de precisar el título de "Tercera Orden» y su origen. En la segunda exponemos los beaterios existentes, muchos de los cuales fueron obligados a convertirse $\mathrm{o}$ a fusionarse con un convento de monjas. Finalmente, abordamos el estudio de terceras en particular profundizando en los distintos aspectos que conformaban su vivir diario.

PALABRAS CLAVE: Tercera Orden Franciscana; mujeres religiosas; terceras; beaterio; actividades económicas

\section{FEMALE MEMBERS OF THE THIRD FRANCISCAN ORDER IN ANDALUSIA AT THE END OF THE MIDDLE AGES}

\begin{abstract}
This paper is focused on the study of the female members of the Third Franciscan Order who lived in Andalusia in the late Middle Ages. Firstly we try to specify the title of «Third Order» and its origin. In the second part we expose the existing communities, many of whom were forced to convert or to merge with a convent of nuns. Finally, we approach the study of tertiaries in particular, by deepening the different aspects of their daily living.
\end{abstract}

KEY WORDS: Third Franciscan Order, religious women; tertiaries; beguinaire; economic activities

Cómo CITAR este artículo / Citation: Pérez González, Silvia María y José Sánchez Herrero. 2020. «Los miembros femeninos de la Tercera Orden Franciscana en Andalucía a finales de la Edad Media». Hispania Sacra LXXII, 145: 25-38. https://doi.org/10.3989/ hs.2020.002

Recibido/Received 19-05-2017

Aceptado/Accepted 25-10-2018

\section{EL TÍTULO DE «TERCERA ORDEN»}

La expresión «Tercera Orden» se ha entendido frecuentemente como «tercera comunidad religiosa», «tercer or-

\footnotetext{
1 spergon@upo.es/

ORCID iD: https://orcid.org/0000-0002-3535-1826

2 josanhe1935@gmail.com /

ORCID iD: https://orcid.org/0000-0003-4926-6777
}

den religioso", en sentido estricto, a partir de cuanto afirmaban las leyendas medievales que atribuían a san Francisco la fundación de tres órdenes: la primera los Frailes Menores, la segunda las Clarisas y la tercera la Tercera Orden, lo que ha sido objeto de larga discusión.

Según las investigaciones hasta el presente realizadas parece que la expresión Tercera Orden (TO), que aparece por primera vez en un testamento de 1292, se refiere a 
la Orden Franciscana, ${ }^{3}$ mientras que en las otras Órdenes Mendicantes este término no aparece sino más tardíamente, en los Dominicos hacia la mitad del siglo XV, en los Carmelitas después de 1450 y regularmente en 1660.

Pero en el testamento de 1292, la expresión «tertii ordinis" no se refiere a la TO de san Francisco, como hoy la entendemos, sino a una orden de los penitentes de san Francisco, de la que el testador era miembro, es decir, a uno de aquellos «poenitentium collegia» de los que habla Gregorio IX, en este caso de san Francisco. Es decir, la expresión TO no se refería a los laicos en general que seguían a san Francisco, sino a un grupo especial de penitentes franciscanos.

Si la expresión TO es tardía, mucho más parece serlo el adjetivo terciario, terciaria, signo claro de que la realidad de la TO entendida en el sentido «de orden que viene después de otras dos» no estaba aún madura, mucho más cuando ni siquiera se usaba el termino Segunda Orden, sino que los documentos hablan de "sororis ordinis nostri».

En conclusión, la expresión TO recibió en sus comienzos diferentes significados: simples laicos, seglares, que tiene un puesto dentro de la estructura de la Iglesia, que vienen después del clero; pero también laicos seculares que deseaban vivir de manera más estricta su vocación cristiana y diferenciándose en esto del común de los fieles, grupos que se unieron a cualquier orden mendicante colocándose después del Primer Orden (de los hermanos) y del Segundo Orden (de las monjas). Más tardíamente indicará una institución más cercana a una auténtica Orden religiosa en sentido estricto y entonces se dividirá en TO regular ( «los Terceros») y la TO secular (la que hoy conocemos como VTO.

Ahora bien, si la terminología de TO, terciario, terciaria es tardía, la realidad que nos interesa está claramente presente desde los orígenes de varias Órdenes mendicantes, pero con otra terminología. Las fuentes antiguas hablan, en efecto, de "hermanos de penitencia», "hermanas de penitencia», "poenitentes», "continentes» (refiriéndose a los casados que habían aceptado la vida penitencial), encarcelados, reclusos, palabras con las que se quiere destacar el sentido penitencial.

\section{«Órdenes de penitencia»}

Los «penitentes», en sus orígenes, pudieron comprender también a los clérigos, fueron un movimiento independiente de las Órdenes religiosas mendicantes, que reunían simplemente a laicos que deseaban vivir una vida ascética o de penitencia. En Italia aparecieron unas «Ordines de Penitentia» ya presentes en Florencia en el hospital de San Galo en 1218 y en el de San Pancracio, $1219 .{ }^{4}$ Se trataba de fraternidades de penitentes voluntarios que se entregan a prácticas devocionales y penitentes y a la caridad pública. Abrían fuera de las puertas de la ciudad sus hospitales, donde recibían a viajeros y caminantes, y donde escuchaban la predicación de los dominicos o de los franciscanos sin ponerse bajo su dependencia.

\footnotetext{
3 Meersseman 1961, 209, no 23 y 1977, 698 y ss.

4 Meersseman 1977, 365 y ss.
}

\section{EL ORIGEN DE LA TO}

\section{Raíces históricas}

Los estudios realizados en los últimos años han confirmado que la obra de san Francisco y su misma conversión se insertan en aquel vasto movimiento penitencial (penitentes) que lo precedió desde varios siglos atrás y que había movido no solo a los simples e individuales fieles laicos, sino también a los clérigos y a familias enteras con la adopción de un estilo de vida comunitario.

En otras palabras la TO no es otra cosa que una ulterior expresión de la espiritualidad de los laicos quienes, desde san Benito, habían preferido unirse a los monasterios en formas muy diferentes: "familiar», "oblato», "oblación» y que, a partir del siglo XIII y con la aparición de las Órdenes mendicantes, encuentran otro modo de expresarse, sin renunciar a su trabajo y al estado conyugal. Son laicos que intentan superar su vida espiritual cristiana ordinaria y que vendrán a ocupar un puesto especial en la estructura de la Iglesia, entre los clérigos y los simples fieles que no adoptan este estilo de vida penitencial.

La obra de san Francisco se inscribe en este contexto, llama también a los laicos, casados y no casados, a constituir una orden de penitencia y no una T.O. Aun aceptando que Francisco diera una propia configuración franciscana a sus penitentes, parece difícil exponer cuáles fueron estas características, ya porque el estatuto penitencial, como hemos afirmado, era anterior a las Órdenes mendicantes, pues el Memoriale propositi de $1221^{5}$ no contiene nada específicamente franciscano. No cita particulares actuaciones pauperísticas, ya porque los Hermanos Menores no se preocuparon de los hermanos penitentes hasta que san Buenaventura (1221-1274) se interesó por ellos, más por justificar la despreocupación de la Orden que por darles estas características, cosa que no ocurrió sino más tarde, cuando de hecho los Hermanos Menores se preocuparon de los laicos penitentes. No será sino la bula Supra montem del papa Nicolás IV de 1289 quien afirmará la calidad de san Francisco como «huius ordinis institutor» refiriéndose a la TO franciscana. ${ }^{6}$

A imitación de san Francisco todas las órdenes mendicantes tuvieron su fraternidad de penitentes. Una diferencia comienza a manifestarse en la Regla que el maestro general de los dominicos, fray Munio de Zamora, preparó en 1285, ${ }^{7}$ cuando quiso que los penitentes, asistidos espiritualmente por sacerdotes dominicos, estuviesen sujetos a la dirección de la Orden.

\section{Tipología de la TO regular y TO secular}

En línea general las TO asumen una fisonomía casi idéntica, pues todas practicaron: la vida común, la vida aislada en la propia casa, la vida eremítica (especialmente como custodios de santuarios), la vida en reclusión, la vida célibe, etc.

Con el tiempo y dentro de los Franciscanos se produjo una distinción entre TO regular y TO secular. Encontramos

5 En el nombre del Padre, el Hijo y del Espíritu Santo. MEMORIAL DEL PROPÓSITO de los hermanos y hermanas de la Penitencia que viven en sus propias casas. Inicios del año del Señor 1221. Aprobado este propósito de vida el 20 de mayo de 1228 por el papa Gregorio IX.

6 Sobre esta cuestión véase más ampliamente tratado en Meersseman 1977, 361.

7 Meersseman 1977, 377-380. 
esta distinción en la constitución "Dum intra» del Concilio Lateranense V, del 19 de diciembre de 1516, aunque sin la calificación aún de «regular»y «secular». Se entiende que la TO regular es posterior a la TO secular, pero con anterioridad a la TO regular existieron en Europa grupos similares: beguinas, begardos, beatas, comunidades religiosas de hombres y de mujeres entregados al cuidado de los hospitales que seguía normalmente una de las Reglas aprobadas, normalmente la de san Agustín, o simplemente costumbres locales.

Dentro de la TO regular han existido y, en parte subsisten hoy, diversas tipologías: terciarios religiosos de votos simples, terciarios que admitían los tres votos religiosos o solo alguno de ellos (el de castidad), asociaciones de terciarios sin votos públicos pero con vida común, terciarios eremitas y terciarios viviendo en conventos juntamente con religiosos de votos solemnes. Pero la característica más importante fue y es que la TO regular se configura de manera análoga a un monasterio o a una Orden o un instituto centralizado, con su propio ministro o superior general. En cambio la TO secular o tercer estado de los casados, estaba y está lógicamente compuesto de gente casada, que vive en un mismo lugar, ciudad o pueblo, relacionada o unida a una de las diferentes Órdenes mendicantes. En sus orígenes eran mixtas, pero la mujer casada tenía que tener el consentimiento de su marido para ingresar en una TO y en la fraternidad no gozaba de autoridad, que permanecía en manos de los hombres, según el uso del tiempo. Se crearon también fraternidades únicamente femeninas, que después de la crisis de los siglos XIV-XV, cuando los terciarios (hombres) perdieron los privilegios de que gozaban en el siglo XIII, quedaron solo las fraternidades femeninas. Este régimen permaneció hasta el siglo XX, cuando las fraternidades volvieron a ser mixtas.

\section{Algunas cuestiones jurídicas}

De lo dicho se deduce que la Orden Tercera secular no era ni es una «Orden religiosa» en sentido estricto, sino solo un "estado», integrado por personas: viudas, casadas, célibes. Los componentes de esta TO secular no eran ni son personas eclesiásticas, "viri religiosi», por lo que a partir del siglo XIV las autoridades comunales dejaron de concederles los privilegios que tenían los «religiosos».

Cuando los penitentes se acercaron a las Órdenes mendicantes aceptaron también el hábito, que los terciarios usaron durante bastante tiempo (un manto, «signum habitus») gris los franciscanos y negro los dominicos. Posteriormente se establece una distinción: los terciarios y las terciarias que habían aceptado una «regularidad» de vida continuaron llevando un hábito siempre similar o cercano al de los religiosos de la Orden mendicante a la que estaban ligados, mientras que los terciarios seculares, en cambio, puesto que el hábito entero resultaba incómodo para su vida en el mundo, adoptaron un escapulario (Ilamado pequeño hábito o grande escapulario) para llevarlo bajo sus vestidos, también de noche o escapulario nocturno.

La Tercera Orden regular se convirtió en el siglo XVI en primera orden, como los Hermanos Menores, los Conventuales y los Capuchinos y tuvo también su Tercera Orden secular. ${ }^{8}$

\footnotetext{
8 Pellicia y Rocca 1992.
}

\section{GRUPOS DE TERCERAS EN ANDALUCía A FinALES DE LA EDAD MEDIA}

A finales de la Edad Media se documentan los siguientes grupos de terceras franciscanas dentro del ámbito andaluz que analizamos individualmente.

San Juan de la Penitencia de Cazorla (Jaén): ${ }^{9}$ Una casa de terciarias adoptó la Regla de clarisas hacia el año 151315. Intervino en la fundación don García de Villarroel, sobrino del Cardenal Cisneros. Gracias a la intervención de don García de Villarroel, Adelantado de Cazorla, Comendador de Carrizosa de la Orden de Santiago, Capitán de la ciudad de Almería y Comisario General y sobre todo, sobrino del Cardenal Arzobispo de Toledo, fray Francisco Ximénez de Cisneros, se permitió el traslado del monasterio al interior de la villa. Esta concesión, además de ser el principal mecenas de la fábrica conventual, le reportó el patronato del convento.

Santa Clara de Andújar (Jaén):10 La tradición afirma que habría sido fundado en 1225 por discípulas de Santa Clara. De ser así, significaría que se trató del primer establecimiento religioso de Andalucía. Sin embargo, las noticias documentales sobre vida religiosa femenina en Andújar se hacen esperar a 1450, fecha en que una comunidad de terciarias creada en 1430 recibió licencia papal para abrazar la regla clarisa. A mediados del siglo XV, consideraba insuficientes sus instalaciones y deseaba expandir su fábrica con unas viviendas que la comunidad había adquirido frente al cenobio primitivo.

Santa Inés de Andújar (Jaén): ${ }^{11}$ En 1451 se autoriza la erección como clarisas de Santa Inés antes perteneciente a tereceras franciscanas a petición de Marina López.

Concepción de Beas de Segura (Jaén):12 Su fundación tuvo lugar en 1507, siendo uno de los primeros monasterios dedicados a la Concepción. Algunas fuentes lo sitúan como monasterio de terceras que tras una serie de problemas se convirtieron a la regla de Santa Clara e incluso intentaron abandonar la dependencia de la Orden por la del diocesano.

Santa Isabel de los Ángeles de Córdoba: ${ }^{13}$ Fue fundado en la segunda mitad del siglo XV en la collación de San Pedro, donde hoy se encuentra parte del Convento de Santa Cruz, es decir en la calle Valderrama, haciendo esquina con la calle del Sol. A partir de 1489 las religiosas pasaron a la que definitivamente sería su casa en la collación de Santa Marina, en la plazuela de Santa Isabel. Entre sus miembros destacó Magdalena de la Cruz, ${ }^{14}$ reconocida como santa viva, que fue abadesa entre 1533 y 1542 . Acabó siendo condenada por la Inquisición por pacto diabólico.

Santa Inés del Valle de Écija (Sevilla): ${ }^{15}$ Se data entre 1482-1487. En 1482, doña Inés Chirino, viuda del capitán y alcalde de Osuna don Luis de Pernía, fundó este monasterio para 70 monjas extramuros de la ciudad. Después se trasladó a los arrabales del norte de la misma, junto al camino que

\footnotetext{
9 Almansa Segura 2003. Serrano Estrella 2008, 773.

10 Graña Cid. CLAUSTRA. Atlas de espiritualidad femenina en los Reinos Peninsulares. Barcelona: Institut de Recerca en Cultures (http:// www.ub.edu/claustra/Monestirs/view/523). Consultado el 18 de febrero de 2017. Serrano Estrella 2008, 210.

11 Serrano Estrella 2008, 102.

12 Serrano Estrella 2008, 790.

13 Graña Cid 2002a y 2011, 187-221.

14 Graña Cid 2002b.

15 Miura Andrades 1992, 51-53 y 1994; Rubio 1953.
} 
iba al santuario de Nuestra Señora del Valle. La fundación definitiva parece datar de 1487.

San Blas de Sevilla: ${ }^{16}$ En 1485 tomó posesión de la ermita de la ermita de San Blas Leonor Díaz, beata. En 1491 los Reyes Católicos ordenaron que se ejecutasen las sentencias dadas a favor de las religiosas de San Blas sobre ciertas huertas y casas, de donde se deduce que ya eran comunidad constituida. Más tarde el beaterio de San Blas se unió a la comunidad del Convento de Santa Inés.

Nuestra Señora de la Concepción de San Juan de la Palma de Sevilla: ${ }^{17}$ Debe su origen a doña Leonor de Ribera en 1474 como emparedamiento bajo la tercera regla de San Francisco. En 1511 se transformó en convento de concepcionistas.

Concepción o Santa Isabel de los Ángeles de Carmona (Sevilla): ${ }^{18}$ El convento fue fundado por Lucía Sánchez de Baeza en 1510 para monjas clarisas, aunque finalmente esta intención se modificó en 1513 al recibir el hábito concepcionista pero de la tercera regla.

Nuestra Señora de la Antigua de Utrera (Sevilla): ${ }^{19}$ Este Beaterio-convento de religiosas de la tercera regla de Santa Clara se situó en la Ermita de Nuestra Señora de la Antigua en 1506. Lo fundaron las emparedadas sevillanas, procedentes de la iglesia de San Miguel de Sevilla, Mencía de Santa María, Leonor de los Ángeles y Constancia de San Francisco. Las llevó desde Sevilla en 1505 Alonso Álvarez Chamorro con bula de Julio II.

Madre de Dios de Jerez de la Frontera (Cádiz):20 El convento de clarisas de Madre de Dios es el resultado de la concentración de las beatas franciscanas existentes en la ciudad de Jerez que, tras el abandono, en 1495, de los observantes del convento de Madre de Dios, para trasladarse al de San Francisco el Real (desalojado por los conventuales) se instalaron en él. La primera noticia documentada que tenemos es la 1504, fecha en la que Catalina Espíndola, mujer de Pedro Martínez de Hinojosa, entrega a Isabel de Melgarejo, su hija, la legítima con el fin de que profese en el convento de Madre de Dios. En igual fecha su hermano Álvaro López hacía donación a María Carrillo, abadesa, Isabel de Cisneros, provisora, Ana González, María de Herrera, Leonor Jiménez, Eufrasia de la Cruz, Francisca Marroquí y Catalina Galindo, monjas profesas en el monasterio de Santa María Madre de Dios de Jerez, de los bienes que había heredado de su padre. ${ }^{21}$ De la cita de las religiosas hemos de llamar la atención sobre el hecho que dos de ellas, Ana González y María de Herrera, eran religiosas de Santa Inés del Valle de Écija en 1499,22 y continúa siéndolo Ana González en febrero de 1504, cuando las monjas astigitanas otorgaron su carta de poder a fray Cristóbal de Villanueva, ${ }^{23}$ para volver a serlo María de Herrera en 1509, cuando venden

\footnotetext{
16 Miura Andrades 1998, 256.

17 Miura Andrades 1998, 254.

18 Miura Andrades 1998, 255.

19 Miura Andrades 1998, 255.

20 Mesa Xinete 1888, 463. Miura Andrades, J. M. 1994. Sancho de Sopranis y Lastra y Terry 1964.

21 1504, enero, 12. Citado por Mesa Xinete, F. 1888, 463. Citado por Miura Andrades 2014, 568-570.

22 1499, mayo, 10. Écija. AGS = Archivo General de Simancas, Casa y Descargo, leg. 1, fol. 285. Citado por Miura Andrades 2014, 568.

${ }_{23} 1504$, febrero, 14. Écija. AGS, Casa y Descargo, leg. 4, fol. 72. Citado por Miura Andrades 2014, 568.
}

unas casas de la dote de Francisca de Valderrama. ${ }^{24}$ Además otras de ellas, Francisca Marroquí y Catalina Galindo tienen en sus apellidos amplias resonancias de la ciudad astigitana. Pensamos que tal comunidad puede considerarse, por los múltiples y frecuentes contactos entre ambas poblaciones fronterizas, filial de Santa Inés del Valle de Écija desde donde, probablemente, llegaran algunas religiosas para estructurar la comunidad.

Reafirma esta opinión el hecho de que, en 1512, nos consta que eran "monjas de Santa Clara de la Tercera Regla» a las que el provisor del arzobispado de Sevilla da copia del acuerdo entre Diego de Deza, arzobispo de Sevilla, y el cabildo de Sevilla, por una parte, y fray Cristóbal de Aguilar, Ministro Provincial de los frailes de la Observancia de San Francisco de la Provincia de Andalucía y de la monjas de Santa Clara de la Tercera Regla de la dicha Provincia, en nombre de la abadesa y monjas del monasterio de Santa Inés del Valle de Écija y de todas las otras religiosas, casas y monasterios de monjas de Santa Clara de la Tercera Regla del arzobispado de Sevilla, sobre el pago del diezmo de sus bienes. ${ }^{25}$

Nuestra Señora de Gracia de Vélez-Málaga (Málaga)::26 La fundación como convento tiene que ver con Beatriz de Arellano. En su testamento, otorgado el 18 de diciembre de 1540 mandaba fundar un convento de clarisas con la advocación de Nuestra Señora de la Concepción. Esta fundación nada tenía que ver con el preexistente convento de terciarias de Nuestra Señora de Gracia, a quien Beatriz de Arellano había legado cinco arrobas de aceite al año y con el que, incluso, había llegado a pleitear. Sin embargo, tras su fallecimiento, sus albaceas testamentarios se pusieron de acuerdo con los regidores del municipio en reunificar ambas comunidades, con lo que se ahorrarían costos. Las cláusulas fundacionales estipulaban para el nuevo convento que no sobrepasase el número de 12 monjas de Vélez-Málaga sin dote. Otras 10 fueron las terciarias de Nuestra Señora de Gracia, que para facilitar la refundición adoptaron la orden segunda, pasando a convertirse en monjas clarisas, sujetas a la observancia de monasterio de San Francisco de la ciudad de Vélez-Málaga.

Concepción de Vélez-Málaga (Málaga): 1512-1540. Sobre la fundación del convento de Granada tenemos dos crónicas. La de Francisco Bermúdez de Pedraza es concisa: «El séptimo es el Monasterio de la Concepción de nuestra Señora, del hábito y regla tercera de san Francisco, sujeto al Ordinario, fundado por Juliana de San Francisco, de nación romana, el año de mil quinientos y treinta. Son sesenta monjas de hábito pardo y escapulario azul, tienen de renta tres mil ducados».27

La segunda crónica de fray Alonso de Torres $^{28}$ es mucho más completa. Comienza por afirmar que al Cabildo del templo de El Salvador de Roma, junto al Palacio Lateranense (Ba-

24 1509, mayo, 16. Écija. APNEC=Archivo de Protocolos Notariales de Écija, Leg. 71. Citado por Miura Andrades 2014, 568.

25 1512, mayo, 21. El acuerdo se conserva en ACS=Archivo de la Catedral de Sevilla, Fondo Histórico General, Leg. 94, doc. n.20/6. Citado por Miura Andrades 2014, 568.

26 Graña Cid. CLAUSTRA. Atlas de espiritualidad femenina en los Reinos Peninsulares. Barcelona: Institut de Recerca en Cultures (http://www.ub.edu/claustra/Monestirs/view/523). Consultado el 18 de febrero de 2017.

27 Bermúdez de Pedraza 1608, 118v.

28 Torres 1683, 863-864. 
sílica de San Juan de Letrán), los Pontífices le concedieron la facultad de erigir iglesias, monasterios y hospitales, que fuesen «miembros de su cuerpo» y estuviesen a su protección. Según el testimonio del Provisor del Arzobispado de Granada, antes de la fundación canónica de este monasterio en 1618, "había dentro de la casa trece religiosas, que vivían según la Regla de la Tercera Orden de nuestro seráfico padre san Francisco y traían el hábito, según y conforme a la dicha Orden, que sin duda es el que hoy conservan, de color negro y escapulario azul, por la Concepción Purísima, que es la advocación y título», monjas de la Tercera Orden regular de san Francisco o beatas que se habían reunido formando una de los muchos grupos que existieron de órdenes de penitencia.

La primera fundación de este monasterio parece se debió a Juliana de san Francisco, de nación romana, siguiendo, sin duda, los privilegios del Cabildo de la Basílica del Salvador de Roma y colocándose bajo la jurisdicción del Ordinario de Granda y no sometidos a alguna de las órdenes existentes. Pero la fundación definitiva tuvo lugar el 23 de noviembre de 1518, a partir de las Letras dadas por el Cabildo de la Basílica de El Salvador de Roma, pero precediendo una bula apostólica del Papa León X del 15 de marzo de 1518, «mandando en una y otra guardasen la regla del Orden Tercero de Penitencia de nuestro seráfico padre san Francisco, con título de la Inmaculada Concepción».

Sin embargo el cumplimiento de dichas bulas tuvo que esperar hasta que doña Leonor Ramírez, vecina de la ciudad de Granada, las presentó al arzobispo don Antonio de Roxas, quien mandó su ejecución el año de mil quinientos veinte y tres.

Beaterio de Vélez-Málaga (Málaga): ${ }^{29}$ Francisco Enríquez y Quiñones había dejado en su testamento una casa en Vélez-Málaga para fundar un hospital. Su única hija, Juana Enríquez, fue su heredera y falleció muy joven. Puesto que Vélez-Málaga contaba ya con hospital, sus albaceas acordaron destinar el legado a un monasterio de monjas, puesto que Vélez-Málaga no contaba con ninguno. El cabildo de la ciudad debió aprobar esta decisión en 1503, fecha que se acepta como fundacional. La casa, hoy desaparecida, se ubicaba en la actual plaza de Rojas. Esta casa la tenían ocupada los frailes franciscanos hasta que en 1508 se trasladaron a su convento, por lo que las mujeres, al hallarse bajo la protección del cabildo civil, recibieron de este alojamiento en una casa del barrio alto, delimitada por las calles Real de la Villa, Subida a la Fortaleza y San Antonio. Esta edificación, hoy no conservada, fue habilitada para la vida en clausura. La vida espiritual de estas mujeres, en realidad beatas, giraba en torno a la imagen de la Virgen de Gracia, que los Reyes Católicos habían traído consigo al tomar la ciudad, donde la dejaron. Sin embargo la fundación tenía que ser aprobada por la autoridad eclesiástica, así como el cambio de uso del legado de Juana Enríquez, lo que aconteció en el año 1512, cuando el papa emitió una bula dando a estas mujeres la orden tercera de San Francisco, pasando pues, a detentar el carácter de terciarias franciscanas.

Nuestra Señora de los Ángeles de Granada: $:^{30}$ Don Rodrigo Ponce de Ocampo, caballero de Santiago, y su esposa

29 Graña Cid. CLAUSTRA. Atlas de espiritualidad femenina en los Reinos Peninsulares. Barcelona: Institut de Recerca en Cultures (http:// www.ub.edu/claustra/Monestirs/view/523). Consultado el $18 \mathrm{de}$ febrero de 2017.

30 Bermúdez de Pedraza 1608. Torres 1683. doña Leonor de Cáceres determinaron fundar en 1538 un convento de terciarias regulares franciscanas. Al morir el fundador sin terminarlo, prosiguieron la obra dos terciarias seglares de Granada, doña Leonor de Saavedra y doña Inés de Jesús. Ambas lo finalizaron en 1540 y profesaron en él, bajo la jurisdicción de los terciarios de Granada durante 30 años. En 1567, con bula de Pío V, profesaron en la Orden de Santa Clara y se sujetaron a la Observancia.

Concepción de Granada: Pocas son las noticias que tenemos de este monasterio. Para situarnos debemos de comenzar recordando que fueron los Reyes Católicos quienes planificaron la fundación de la Orden femenina franciscana y que su preocupación recayó, como era lógico, sobre la Orden de Santa Clara. Doña Isabel, la católica, fundó en Granada el monasterio de Santa Isabel la Real al que concedió copiosas rentas. ${ }^{31}$ Monjas de Santa Isabel la Real de Granada poblaron el de la Concepción de Málaga. ${ }^{32}$

María del Mar Graña Cid nos informa de «agrupaciones de beatas o mulieres religiosas que vivían en comunidad sin sujetarse a ninguna de las reglas oficialmente reconocidas, quizá como respuesta al previo influjo franciscano, que habría tenido tiempo para extenderse y consolidarse, y quizá por los márgenes más amplios que los largos periodos de sede vacante que caracterizan estos años propiciaban ${ }^{33}$

Debemos, también, tener en cuenta que entre 1454 y 1492 doña Beatriz de Silva fundaba en Toledo una congregación de monjas de estricta clausura en honor de la Inmaculada Concepción o Concepcionistas, de hábito blanco, que primero recibieron la Regla de Cister, posteriormente los dominicos trataron de agregárselas $y$, finalmente, frey Juan de Tolosa, franciscano, consiguió que la Orden no desapareciera y adoptara la regla de las clarisas y quedara bajo la dirección de los frailes menores.

Con estos preámbulos podemos concluir que la fundación de la Concepción de Vélez Málaga se debió a un grupo de mujeres beatas o autotituladas como terciarias franciscanas que se constituyeron como orden religiosa bajo la obediencia episcopal. Las que en 1512 «obtenían facultad de Julio II para constituirse en convento de terciarias regulares bajo la advocación de Santa María de Gracia y la sujeción episcopal; en 1518, a instancias de doña Leonor Ramírez, concedía León $\mathrm{X}$ que su comunidad de trece mujeres beatas de Granada guardase la tercera orden con la advocación de la Inmaculada Concepción, aunque oficialmente no se reconoce esa fundación hasta $1523 » .^{34}$

Nada tienen que ver estos conventos con el título de Concepción con las Concepcionistas fundadas por doña Beatriz de Silva.

\section{LAS TERCERAS Y SUS VIVIR COTIDIANO}

\section{Cuestiones terminológicas}

De la documentación consultada podemos extraer una primera conclusión: en la sociedad andaluza bajomedieval, al menos en un grupo con una formación intelectual especial como eran los escribanos públicos, no existía una idea clara de

31 Torres 1683, 395.

32 Graña Cid 1997, 115.

33 Ibídem, 116.

34 Ibídem, 117. 
lo que era una tercera. Es más, jamás utilizan este concepto para referirse a ellas, sino que lo aplicamos nosotros de acuerdo con las bendiciones o consagraciones por ellas recibidas, puesto que la variedad terminológica empleada es enormemente rica. Ello no hace sino subrayar la indefinición existente en relación con esta forma de religiosidad femenina laica.

El término utilizado en un mayor número de ocasiones es el de freila: freila de la Tercera Regla de san Francisco. ${ }^{35}$ La denominación más empleada en segundo lugar es la de honesta: honesta de la Tercera Regla de San Francisco. ${ }^{36}$ En tercer lugar figura el término beata: beata de la Orden de san Francisco. ${ }^{37}$ En un menor número de casos se hace referencia a las terceras como religiosas: religiosa de la Tercera Regla de san Francisco; ${ }^{38} \mathrm{o}$ aplicándoles la denominación de hermana: hermana de la Orden de san Francisco. ${ }^{39}$

Los escribanos públicos y, suponemos, el resto de la sociedad andaluza bajomedieval, eran conscientes de que estas mujeres habían optado por una forma peculiar de religiosidad, distinguían perfectamente la Orden a la que pertenecían, sin duda ayudados por los hábitos que vestían, pero a la hora de otorgarles una denominación precisa y definitoria de su situación carecían del término exacto que debían aplicar. El mismo escribano emplea indistintamente varios términos, lo que no es más que el reflejo de un fenómeno que la sociedad contemporánea siente como propio y cotidiano, pero a la vez oscuro e indeterminado. Quizás esta indefinición pueda hacerse extensiva a sus protagonistas: ellas mismas se autodenominaban bajo distintas formas por lo que el escribano carecía de una denominación precisa y definitoria de su situación y de un término exacto que debían aplicar.

Esta caracterización que se acaba de presentar no está exenta de problemas porque, por ejemplo, no siempre es fácil distinguir cuándo estamos ante un rasgo lingüístico específico y cuándo ante un rasgo general. Como han señalado diversos autores en este campo los grados de especificidad posibles son diversos porque, junto a las formas que solo pertenecen a la competencia de los especialistas en un ámbito específico, habría que incluir aquellas que pertenecen a la competencia de los especialistas y a la competencia pasiva de los demás hablantes, aquellas que son utilizadas en la lengua general y en la de especialidad, pero con acepciones funcionalmente bien diferenciadas, y aquellas que forman parte de la competencia de los especialistas y de los no especialistas, aunque su uso es mucho más frecuente en la esfera de los primeros. ${ }^{40}$

\section{Ingreso en la orden}

La documentación estudiada nos permite conocer detalladamente el ritual de ordenación de dos terceras franciscanas, Constanza de la Cruz, beata romana estante en Jerez,

35 AHPS=Archivo Histórico Provincial Sevilla. Sección Protocolos. Leg.17422. Año 1496. Fol.536r., Leg.17424. Año 1498. Fols.97r., 215v., Leg.1500. Año 1502. Fol.750r., Leg.17426. Año 1500. Fol.167v., Leg.17427. Año 1501. Sin foliar.

36 AHPS. Sección Protocolos. Leg.2158. Año 1500. Fol.107v. Leg.3212. Año 1485. Fol.2r., Leg. 2160. Año 1501. Fol. 196r, Leg.2161. Año 1502. Fol.43r.

37 Leg. 9102. Año 1504. Fol. 170v

38 AHPS. Sección Protocolos. Leg.2163. Año 1503. Fol.5r.

39 AHPS. Sección Protocolos. Leg.9099. Año 1495. Fol.130v.

40 Cedergre 1983, 150. Sánchez García 2009, 157.
Aldonza Rodríguez y Leonor de Ortega. En el caso de Constanza ${ }^{41}$ la ceremonia, que se desarrolló a hora de vísperas en la capilla mayor de la iglesia del Convento de San Francisco de Jerez de la Frontera, fue oficiada por el padre guardián de la Casa, fray Jorge, en presencia de los frailes pertenecientes a la misma. Constanza declaró, tras ser interrogada por el guardián, que quería ser freila beata de la Tercera Orden y Regla de san Francisco, lo que viene a ratificar lo anteriormente expuesto sobre la indefinición de este colectivo religioso femenino. A continuación le informó sobre lo que estaba obligada a cumplir y obedecer, tras lo cual se arrodilló delante del guardián para hacer profesión, este tomó sus manos entre las suyas y Constanza pronunció en voz alta su voto y promesa por la Virgen, san Francisco y todos los santos de guardar en todo tiempo los mandamientos de Dios y de la Tercera Orden de san Francisco así como de no partir ni salir de la Orden.

El testimonio del ingreso en la Orden Tercera de san Francisco de Aldonza Rodríguez, que tuvo lugar el 25 de octubre de 1496, es más completo. La ceremonia, que tuvo lugar en el Convento de San Francisco de Sevilla, fue oficiada por el custodio de la Casa, el doctor fray Antonio de los Ríos, vicario y ministro por el reverendo maestro fray Sancho de Hontañón, ministro de los frailes menores, monjas de Santa Clara, frailes y freilas de la Tercera Regla de san Francisco de la provincia de Sevilla. En primer lugar le preguntó si quería ser freila de la Tercera Regla de san Francisco, a lo que la citada Aldonza respondió afirmativamente. A continuación fray Antonio la conminó a hacer profesión en sus manos y ella, en la mejor forma y manera que podía, así lo hizo. Luego a instancia de fray Antonio hubo de declarar públicamente que quería ser freila de la Tercera Regla de la Orden de san Francisco y llevar su hábito. Tras pronunciar su voluntad fray Antonio cogió sus manos entre las suyas y ella tomó una candelilla y repitió tres palabras que el fraile le dijo, seguidas de la promesa a Dios, santa María, san Pedro, san Pablo y el santo padre san Francisco, de que guardaría la Tercera Regla de la Orden de san Francisco, así como observar obediencia y castidad. Finalmente, fray Antonio la bendijo.

Como puede observarse, el parecido entre las fórmulas empleadas en el ingreso en una Orden Tercera y las características del contrato de vasallaje son evidentes: volo, inmixtio manuum, juramento de fidelidad. ${ }^{42}$ Desconocemos si en el caso de las terceras se prescindía del ósculo.

Los detalles de la ceremonia se muestran menos desarrollados en el testimonio prestado por el reverendo padre fray Sancho de Hontañón, ministro de los frailes menores, monjas de Santa Clara, frailes y freilas de la Tercera Regla de san Francisco de la provincia de Sevilla, en relación con el ingreso en esta Orden de Leonor de Ortega. ${ }^{43}$ Simplemente se limitó a testimoniar que Leonor hizo profesión en sus manos, segund lo acostumbran a faser las otras freylas, en el Convento de San Francisco y ante varios testigos.

De estos ejemplos podemos sacar algunas conclusiones: los ministros encargados de oficiar la ceremonia eran personas relevantes en la Orden, el ministro general de la provincia de Sevilla o el custodio del Convento de San

41 AMJFPN=Archivo Municipal Jerez Frontera Protocolos Notariales. Rodrigo de Rus. 7 de octubre de 1537. Fol.995v.

42 Alvarado Planas y Pérez Marcos 2010. Bisson 1989, 170.

43 AHPS. Sección Protocolos. Leg.3215. Año 1495. Fol.17v. 
Francisco. $Y$ son precisamente estos institutos, la Casa Grande hispalense y el cenobio jerezano, el escenario donde había de desarrollarse.

Tras el ingreso las terceras, no sabemos si todas o solo algunas de ellas, llevaban un hábito distintivo de la Orden en la que había hecho la profesión. La documentación consultada es enormemente parca en lo que a esta cuestión se refiere. Solo contamos con una única referencia de una tercera franciscana que vestía el hábito correspondiente: Ana Rodríguez la farfana. ${ }^{44}$ Precisamente el hecho de vestir honesto áuito fue uno de los elementos considerados por la Cofradía de San Bernardo de la collación de San Juan, heredera de los bienes del racionero Francisco Fernández, tío de la citada Ana, para entregarle unas casas que el clérigo le había dejado en su testamento con la condición de que se casase o ingresase en alguna orden. Ana Rodríguez optó por una forma de vida religiosa fuera de un recinto monástico, superando el condicionante impuesto por su tío para heredar las casas al vivir de acuerdo con la Tercera Regla franciscana tanto en las actitudes internas como en las manifestaciones externas que la distinguían.

La vinculación con el convento franciscano masculino de su ciudad se va a mantener durante toda la existencia de estas mujeres. Juana Sánchez, donada o freila de la Orden Tercera en 1417 y madre de fray Juan de Todos los Santos, Custodio de la Custodia de Sevilla, ${ }^{45}$ y otras terciarias franciscanas se encargaban de atender la Iglesia de San Francisco. ${ }^{46}$ Leonor Rodríguez, la beata, ${ }^{47}$ se autodenominó "freila» del monasterio de San Francisco. ${ }^{48}$ Otra prueba de esta vinculación son las últimas voluntades de las terceras, que no son muy abundantes. Desconocemos las razones que justifican el bajo número de testamentos ${ }^{49}$ a ellas pertenecientes: carecían de bienes que dejar en herencia, no necesitaban dejar establecidos los oficios de difuntos que debían celebrarles, pues de ello se ocupaban sus hermanos y hermanas en religión, celebrando, con una diferenciación litúrgica por sexos, los ofiçios que los frailes acostumbran faser a otras personas freilas de su regla, ${ }^{50}$ etc.

El 28 de febrero de 1477 dictó su testamento Inés Gómez, freila de la Tercera Regla de san Francisco. ${ }^{51}$ Su vinculación con la Casa franciscana de Sevilla era notoria: se mandó enterrar en la iglesia del monasterio ${ }^{52}$ sin ningún tipo de boato ni ornamentación en las ceremonias de inhumación ni en la sepultura, que tenía en propiedad. Los frailes debían celebrarle los oficios propios de su condición como acostumbraban a realizar con otros miembros de la Orden, y nombró albacea de su testamento a fray Francisco, fraile profeso del convento. La única propiedad que dejó en herencia fue su sepultura, siendo

\footnotetext{
44 AHPS. Sección Protocolos. Leg.17422. Año 1496. Fol.536r.

45 1417, octubre, 18. Juana Sánchez, donada o freila de la Orden Tercera, dona al convento de San Francisco de Sevilla dos pares de casas. Rubio 1953, documentos 244, 246, 719-720.

46 Graña Cid 1993, 701.

47 1431, octubre, 1. AMS, Sec. 16, carpeta 5a , no 128 . Citado en Miura Andrades 1998, 238.

48 1480, agosto, 7. Sevilla. ADPS=Archivo Diputación Provincia Sevilla, Espíritu Santo, Leg. 37, inserto en un documento de 1524. Citado en: Miura Andrades 1998, 239.

49 Bazán Díaz y González Mínguez 2005.

50 AHPS. Sección Protocolos. Leg. 17415. Año 1477. Fol. 108v

51 AHPS. Sección Protocolos. Leg.17415. Fol.108v.

52 Bejarano Rubio 1990, 51-53.
}

su receptora su sobrina Inés González. Por tanto, el espíritu de pobreza y austeridad que imponía la Orden franciscana preside el contenido testamentario.

Los ejemplos reseñados evidencian que las terceras se sentían vinculadas a la casa masculina de la Orden franciscana y en ningún momento con un convento femenino. Precisamente no quieren vincularse con el instituto donde se desarrollaba la vida de clausura de las monjas, a las que ellas de forma expresa habían renunciado y de la que intencionadamente querían desvincularse reivindicando su pertenencia a la Orden a partir de su vinculación espiritual e institucional las casas de los frailes. Por su parte los franciscanos actuaron como impulsores de esta forma de religiosidad femenina laica, así como de instrumentos de institucionalización de la misma. ${ }^{53}$

\section{Vida en sociedad}

Las terceras se encontraban perfectamente incardinadas en la sociedad a la que pertenecían. Estas mujeres, pese a la vinculación con el convento de la Orden en la que profesaban, vivían solas en sus casas como un vecino más, lo que refuerza su carácter laical. ${ }^{54}$ Por otro lado, esa estrecha relación con la sociedad a la que pertenecían las llevó a cumplir para ella funciones derivadas también de su peculiar forma de vivir la religión, de lo que hemos denominado el prestigio socio-religioso de las terceras. De esta manera el hecho de haber optado por una forma personal de religiosidad presente en su vivir diario, las revestía de una consideración especial y las hacía portadoras de unos valores de especial reconocimiento social. Por ello fueron designadas como albaceas testamentarios y se les encomendó el cumplimiento de mandas pro remedio animae. $^{55}$

\section{Las actividades económicas}

Algunos miembros femeninos de la Orden tercera franciscana participaron en actividades económicamente muy lucrativas como el mercado inmobiliario, el mundo de las finanzas y el comercial, al tiempo que se insertaron en el mercado laboral. No obstante queremos subrayar que la situación de prosperidad económica no es general para todo el colectivo, pues se trata de las terceras que disponían de los medios suficientes como para negociar y acudir ante el escribano público para ratificar sus actuaciones económicas. ${ }^{56}$ En el extremo opuesto,

53 Graña Cid 2006, 285.

54 Doña Brianda de Villavicencio, viuda del veinticuatro Fernán Ruiz Cabeza de Vaca, en la collación de San Marcos (AMJFPN. Rodrigo de Rus. 2 de mayo de 1536. Fol.370r.); Isabel de Sierra, en la collación de San Miguel (AMJFPN. Alonso Sarmiento. 30 de junio de 1535. Fol.453v.); Luisa de Santana, en la collación de Santiago (AMJFPN. Alonso Sarmiento. 19 de febrero de 1532. Fol.138r.); y María de la Cruz, en la collación de San Miguel (AMJFPN. Baltasar de Lueña. 4 de enero de 1537. Fol.38r.); María Rodríguez, viuda, en la collación de San Miguel (AMJFPN. Rodrigo de Rus. 14 de mayo de 1536. Fol.421r.).

55 Pérez González 2005, 113-114.

56 Un ejemplo de tercera muy poderosa económicamente es el de Juana de Leiva, hija de Alonso Ortiz y Mencía de Zúñiga, quien siguió la vocación de su tía-abuela Leonor de Zúñiga "La Buena», y también fue beata de la Orden Tercera de San Francisco, aunque la documentación nos la presenta como honesta. Ello no le impidió fundar, en 1504, un 
existieron numerosos casos de situación de pobreza ${ }^{57}$ tan evidentes que los concejos incluyeron a estas mujeres entre los beneficiarios de las limosnas repartidas entre diversos colectivos. $^{58}$

\section{El mercado inmobiliario}

El mercado inmobiliario representa unos de los ámbitos económicos con mayor actividad a finales de la Edad Media. ${ }^{59}$ La documentación pone de manifiesto los diferentes negocios a los que son sometidos los inmuebles, aunque la descripción de los mismos es muy poco ilustrativa. En ella, bajo la denominación de casas, en plural, se hace referencia a un conjunto formado por unos palacios, soberados y corral, elementos que pueden estar presentes en su totalidad o en cantidad variable. ${ }^{60}$ No podemos dilucidar el tamaño de estos inmuebles y tampoco podemos averiguarlo de acuerdo con los alquileres establecidos en los contratos, pues la cantidad estipulada debió estar en proporción directa con factores ${ }^{61}$ como su localización dentro del espacio urbano, las condiciones de conservación, los materiales constructivos y el contar con alguna infraestructura especial como pozos, pilas, cocinas, mobiliario, etc.

Dentro del patrimonio de las terceras las casas tienen un predominio absoluto. No podemos olvidar que su existencia se desarrollaba en un ámbito eminentemente urbano, en este caso la ciudad de Sevilla, donde realizaban todas las actividades vinculadas a su vivir cotidiano. Por tanto, debió existir una clara preferencia por unos bienes localizados en esa ciudad en la que las terceras están insertas y donde podían ejercer un control más eficiente de los mismos. La supervisión del cumplimiento de los contratos y de la conservación de su patrimonio inmobiliario podían realizarla sin tener que desplazarse fuera de la ciudad.

Las cuatro casas propiedad de terceras que documentamos estaban distribuidas por la ciudad de Sevilla, con la excepción de una de ellas, que se localizaba en Jaén. ${ }^{62}$ Las collaciones hispalenses donde se encuentran dichas casas son San Vicente, ${ }^{63}$ San Miguel ${ }^{64}$ y San Marcos. ${ }^{65}$

En la mayoría de los casos desconocemos los procesos previos y necesarios por los que estas casas que formaban parte del patrimonio de las terceras se incorporaron al mismo, pues la documentación guarda un absoluto silencio al respecto y no contamos con ningún contrato de compra. Un ejemplo consignado se refiere a la herencia de unas

mayorazgo con sus bienes en la persona de su sobrino Alonso, hijo de su hermano Fernando, y con cargo del entierro y altar de su tía-abuela en la capilla mayor del convento de San Francisco (Miura Andrades 1998, 241).

57 Miura Andrades $(1998,239)$ documenta numerosos casos de terceras pobres como Catalina Muñoz y Juana Sánchez, vecinas de Santa Marina, en 1438 y en 1444 vivía en la collación San Juan de la Palma Juana Fernández, beata pobre.

58 Ibídem, 238-239.

59 Collantes de Terán Sánchez 1988 y 2007 b.

60 Carlé 1982

61 Collantes de Terán Sánchez 2007a. Álvarez Fernández y Suárez Beltrán 2015, 80.

62 AHPS. Sección Protocolos. Leg.2161. Año 1502. Fol.374v

63 AHPS. Sección Protocolos. Leg.17422. Año 1496. Fol.536r.

64 AHPS. Sección Protocolos. Leg.17424. Año 1498. Fol.97r.

65 AHPS. Sección Protocolos. Leg.17427. Año 1501. Sin foliar. casas en la collación de San Vicente por Ana Rodríguez la farfana. ${ }^{66}$ El tío de la citada Ana, el racionero de la Catedral Francisco Fernández, había mandado en su testamento 15.000 maravedís como dote para que su sobrina se casase o ingresase en algún convento o monasterio. La heredera de los bienes del racionero, la Cofradía de San Bernardo de la collación de San Juan, teniendo en cuenta que la citada Ana non era persona para casarse nin entrar en religión por çiertas ocupaçiones e enfermedades, efectuó el pago de los 15.000 maravedís entregándole las casas de San Vicente. Las razones aducidas por la Cofradía para ello fueron el deseo de practicar con ella la caridad, descargar el alma del racionero y que, tras profesar en la Tercera Regla de san Francisco, viue en áuito onesto e en seruiçio de Dios Nuestro Señor.

Por su parte Leonor Díaz tomó posesión en 1485 de la casa y ermita de San Blas, donde se había retirado la fundadora del convento de Santa Inés, ${ }^{67}$ doña María Coronel, antes de la erección del mismo. ${ }^{68}$

Los contratos suscritos por las terceras en relación con sus casas consisten en una venta (Catalina Díaz vendió unas casas por 8.400 maravedís) ${ }^{69}$ y un arrendamiento: Leonor Fernández de Varea alquiló unas casas por un periodo de un año y una renta de 1.400 maravedís que debían pagarse trimestralmente y cuatro gallinas pagaderas ocho días antes de Navidad. ${ }^{70}$ La escasez de contratos de arrendamientos nos impide determinar si las terceras ejercían un control exhaustivo de sus propiedades, tal como lo indican el periodo corto de alquiler o si, por el contrario, preferían garantizarse unas rentas fijas durante un periodo prolongado de tiempo (contratos de tres vidas), sin necesidad de estar atentas a la renovación de los contratos cada cierto tiempo.

Lo cierto es que en la época estudiada existía entre los particulares, a diferencia de las instituciones, ${ }^{71}$ una predilección por el contrato de corta duración, preferentemente anual. Este predominio de contratos de arrendamiento de tiempo limitado responde a un control exhaustivo de la economía de los particulares, al tiempo que evidencia una mentalidad mercantilista, un afán de lucro, pues la renovación anual de los contratos permitiría elevar las rentas cuando unas circunstancias de prosperidad económica lo hiciesen posible y así adecuarlos a los incrementos en el coste de la vida. ${ }^{72}$ Por tanto, nos encontramos con un mercado inmobiliario muy dinámico, donde la suscripción de contratos de arrendamiento era constante, con cambios continuos en los inquilinos.

Entre las terceras no solo documentamos propietarias de casas, sino que también algunos de sus miembros alquilaron ciertas propiedades al carecer, suponemos, de las suyas propias. En el ejemplo consignado se trata de contratos de larga duración, por la vida de la tercera, fijándose la renta en 700 maravedís pagados por tercios y dos gallinas, entregadas ocho días antes de Navidad. ${ }^{73}$

66 AHPS. Sección Protocolos. Leg.17422. Año 1496. Fol.536r.

67 Valdivieso González y Morales Martínez 1991, 77-102.

68 1485, s.m., s.d. Archivo del Convento de Santa Inés de Sevilla, Leg. 1, n. 1, "Libro Registro de Escrituras», apunte $72, f^{\circ} 145 r^{\circ}$. Citado por: Miura Andrades 1998, 237.

69 AHPS. Sección Protocolos. Leg.17424. Año 1498. Fol.97r.

70 AHPS. Sección Protocolos. Leg.17427. Año 1501. Sin foliar

71 Pérez González 2016, 510.

72 Cabrera Sánchez 1993, 115.

73 AHPS. Sección Protocolos. Leg.17425. Año 1499. Fol.458v. 


\section{Actividades financieras}

Las terceras, al igual que otros miembros de colectivos femeninos, ${ }^{74}$ se dedicaron al préstamo de dinero. Esta actividad desempeñó un papel muy importante dentro de una estructura económica donde no existían los bancos ${ }^{75}$ ni una regulación en torno a los prestamistas. Esta escasez de una infraestructura favoreció el que numerosas personas pudieran participar en diferentes actividades que podían ofrecerles una alta rentabilidad a su inversión. ${ }^{76}$ Por otro lado en periodos de inflación el dinero atesorado perdía su valor provocando una bajada del poder adquisitivo. De esta forma quienes contaban con dinero atesorado tenían a su disposición diferentes maneras de invertirlo de forma conveniente y segura.

Durante el periodo medieval la práctica del préstamo de dinero experimentó diversas transformaciones en lo que se refiere tanto al significado social como económico del crédito. ${ }^{77}$ Existían elementos de importancia capital tales como la reputación del prestamista y su honestidad, al mismo tiempo que era fundamental elegir a personas que ofreciesen las suficientes garantías para devolver el dinero prestado de acuerdo con las condiciones establecidas entre ambas partes. ${ }^{78}$

Las actividades de préstamo desarrolladas durante la Edad Media se caracterizaron por su marcado carácter local, pues se daban entre personas que tenían un mutuo conocimiento. En un primer momento casi todos los préstamos carecieron de un carácter profesional y se basaron en contratos no siempre ratificados legalmente que unían a vecinos y conocidos. Pero a partir del siglo XV el desarrollo de un mercado claramente expansionista condicionó que las bases sobre las que descansaba el préstamo de dinero tuvieran un carácter más legal. De esta forma las relaciones entre los distintos agentes que intervenían en estas operaciones experimentaron una redefinición en el sentido de que la confianza personal fue reemplazada por términos de igualdad contractual. ${ }^{79} \mathrm{Al}$ hacerse más complejos los mecanismos del crédito, este ya no podía fundamentarse en un elemento tan inestable como la confianza hacia el peticionario del préstamo. Por el contrario el prestamista exigió una rigurosa puesta por escrito del préstamo y su ratificación por el escribano público, como prueba legal del acto y como garantía de su restitución bajo el cumplimiento de distintas clausulas condenatorias en caso de no devolución de la cantidad prestada con sus correspondientes intereses.

En la obtención del beneficio a partir del dinero que era objeto de préstamo, el interés resultaba fundamental en el marco de una economía inflacionista pues de esta forma el poder adquisitivo del dinero se mantenía en un nivel constante. Para obtener una ganancia de la inversión realizada, esta debía ser cargada con una cantidad superior a la tasa de inflación. El valor del interés no quedaba registrado debido a la prohibición por parte de la Iglesia de

\footnotetext{
74 Lemire 2001, 18-23.

75 Monguio Becher 1978, 50.

76 Colombo 2016, 257.

77 Bourin 2007, 108.

78 Tittler 1994, 255.

79 Así sucede en el ámbito andaluz, mientras que en el mundo británico este se dio con posterioridad, a partir de los siglos XVI y XVII
} (Muldrew 1998, 7). la usura. ${ }^{80}$ En su lugar el interés se ocultaba dentro de la cantidad total que debe ser pagada por el deudor, bajo la fórmula que los juristas denominan mutuo oneroso.

Dentro de las actividades vinculadas al préstamo documentamos terceras que pusieron en práctica la fórmula de la venta de rentas. En la época estudiada tanto Sevilla como Jerez de la Frontera eran importantes ciudades comerciales con un destacado desarrollo de la economía monetaria. Sin embargo a lo largo del periodo estudiado las dificultades monetarias eran evidentes así como la falta de liquidez. ${ }^{81}$ Además el desarrollo de la economía monetaria no benefició de igual forma a todos los vecinos, que sí se vieron afectados por los resultados de la misma puesto que los precios subían y su poder adquisitivo se reducía. La necesidad de dinero se intentó paliar a través de distintas fórmulas. Una de ellas fue los sistemas de crédito.

Desde fines del siglo XV existían dos supuestos básicos para el desarrollo de los sistemas de crédito: una persona necesitada de dinero y el capitalista que deseaba hacer fructificar los ahorros monetarios de que disponía. En estos momentos la normativa de la Iglesia sobre la usura había sobrepasado ampliamente los límites establecidos por el Derecho canónico. El freno a cualquier operación de crédito era evidente, aunque ello no impidió el desarrollo de fórmulas financieras. En la época estudiada se van a poner en práctica medios indirectos para prestar dinero y recibir lo prestado en cantidad superior a través de la entrega diferida. ${ }^{82}$ Una de estas fórmulas fue la compra de rentas. Se trataba de una operación según la cual un propietario vendía un censo o tributo perpetuo sobre sus bienes por una cierta cantidad de dinero. El proceso consistía en que un propietario necesitado de dinero suscribía un contrato similar a una compra-venta. El bien vendido era una parte de lo que rentaba la propiedad, que quedaba sujeta a perpetuidad a un canon anual que debía entregar al comprador. En la operación el propietario conseguía la cantidad de dinero líquido que precisaba, mientras el comprador efectuaba una inversión de capital de la que iba a percibir anualmente unos ingresos, pero no la devolución del principal. La fórmula en sí misma no se puede considerar como un auténtico préstamo de capital, puesto que en este se exigía el reembolso del capital en un tiempo determinado y en el caso de la compra de rentas el vendedor recibía el capital para siempre sin la obligación de devolverlo en un plazo concreto. ${ }^{83}$

Hubo terceras que estuvieron perfectamente informadas y preparadas para acudir a esta forma de préstamo disfrazado bajo la fórmula de la compra de rentas. Es el caso de María de la Cruz, vecina de Jerez, quien vendió 5.000 maravedís por 500 maravedís situados sobre unas casas en la collación de San Miguel. La cantidad prestada son los 5.000 maravedís que la tercera cobraría a perpetuidad a razón de 500 maravedís anuales. La garantía del pago eran las casas. ${ }^{84}$ En el caso de Sevilla contamos con el ejemplo de Ana Rodríguez, quien prestó 3.000 maravedís a cambio

80 Benito Ruano 1970. Clavero 1979. García de Valdeavellano 1973. Nelson 1969.

81 Borrero Fernández 1986, 233.

82 Se trata de medios simulados in fraudem usurae. Clavero Salvador 1977.

83 De Almeida Costa 1961, 78.

84 AMJFPN. Baltasar de Lueña. 4 de enero de 1537. Fol.38r. 
de 300 maravedís anuales pagados a perpetuidad, siendo el bien garante del préstamo unas casas en la collación de San Vicente. ${ }^{85}$

\section{Actividades comerciales}

Además de sus obligaciones religiosas, hubo terceras que se dedicaron a actividades con un carácter eminentemente comercial. Desde finales del siglo XV el Reino de Sevilla se convirtió en el centro fundamental de la economía castellana. Esta zona constituía una encrucijada comercial, que actuaba como zona de contacto de los principales núcleos mercantiles de la época. ${ }^{86}$ De importancia muy destacada fueron las relaciones con el Atlántico septentrional, que no se limitaban al intercambio bilateral de productos. Las mercancías que desde el Norte llegaban a las costas atlánticas andaluzas abastecían tanto al mercado local como a los del interior de Castilla, o seguían hasta lugares más alejados en el ámbito mediterráneo o atlántico..$^{87}$ En el sentido contrario, los productos recogidos en la Baja Andalucía para su exportación eran enormemente variados, ya que procedían de diversas zonas de producción.

A este complejo comercio contribuyó la diversidad de sus agentes. Por un lado, un amplio abanico de comerciantes castellanos y extranjeros, que controlaban diversos mercados. Por otro lado, la colaboración entre mercaderes y transportistas de orígenes diversos. Finalmente, la convergencia de relaciones puramente comerciales con otras de carácter pirático. ${ }^{88}$

Entre esos comerciantes documentamos a las terceras que son objeto de nuestro estudio. Actuaron como intermediarias en negocios que, en principio, requerían una cierta especialización en un ámbito de predominio masculino en cuanto a sus intervinientes. Se evidencia al mismo tiempo un profundo conocimiento del mercado de la ciudad y de los productos que mejor salida tenían y mayores beneficios reportaban, donde la intervención femenina era muy minoritaria. Adquirieron los conocimientos que exigían y contactaron con los demandantes de tales productos, negociando para obtener los más pingües beneficios.

Es el caso de la tercera franciscana Catalina de la $\mathrm{Cruz}^{89}$ que estaba especializada en el tráfico del azúcar blanco de pilón. ${ }^{90}$ Las cantidades con las que comercializaba eran considerables: 75 arrobas (862,5 kilos, a 11 kilos y 502 gramos la arroba), apreciada la arroba en 406.66 maravedís, y una caja valorada en 4.800 maravedís, que debía contener, atendiendo a las cifras indicadas, unas 11.8 arrobas (135,72 kilos). Las cantidades consignadas son apreciables, por lo que cabe pensar que la citada Catalina de la Cruz era un importante agente comercial en el tráfico del azúcar, situación que se sale del común denominador de las terceras franciscanas.

En la época estudiada el azúcar no tenía un consumo tan extendido como en la actualidad. Por este motivo su precio

85 AHPS. Sección Protocolos. Leg.2158. Año 1500. Fol.107v.

86 Aznar Vallejo 2003, 103.

87 Sevillano Colom 1970, 364.

88 Aznar Vallejo 1997, 419.

89 AHPS. Sección Protocolos. Leg.2158. Fol.107v.

90 Se trata de un azúcar refinado, obtenido en panes de forma cónica. Para la tipología de azúcares en este periodo véase: Ashtor 1981, 233-236. era elevado y solo podían acceder a ella quienes poseían los suficientes recursos económicos, mientras que los grupos menos pudientes empleaban la miel como edulcorante. ${ }^{91}$ Los fines fundamentales del azúcar eran la medicina y la farmacia, y al tratarse de un producto de lujo las redes comerciales por las que circulaba tenían un alcance corto. ${ }^{92}$

\section{Actividades profesionales}

La mayoría de las terceras no parecen desarrollar una actividad profesional, cumpliendo así con el espíritu franciscano de prescindir del trabajo como fuente de ingresos y realizar tan solo el necesario para subsistir, a excepción de la citada Catalina de la Cruz. No era este el caso de Teresa López, ${ }^{93}$ tercera franciscana, que trabajaba como criada en casa de Alfonso López, curtidor. Los servicios que le prestó durante cuatro años y cuatro meses le reportaron unos ingresos de 6.800 maravedís, una cantidad bastante superior a lo necesario para garantizar la subsistencia.

Para el periodo analizado el servicio doméstico ya no se fundamentaba, como sucedía anteriormente, en una red de muy diversas interacciones que incluía conceptos como la lealtad, la protección e, incluso, derechos de propiedad. ${ }^{94}$ Una de las bases de este sistema era una fuerte jerarquización que hacía completamente imposible el ascenso social y limitaba la obtención de cualquier tipo de objetivo personal. ${ }^{95}$

Pero a fines de la Edad Media el carácter del trabajo doméstico comenzó a cambiar hacia un sistema de trabajo remunerado, que permitía a los criados negociar las condiciones laborales con quienes los empleaban. Con ello, y de forma progresiva, su remuneración pasó a estar sujeta a las condiciones del mercado para cambiar su posición o ascender socialmente. Dentro del desarrollo de la cultura del consumismo fue surgiendo un concepto del servicio doméstico determinado por las ideas de producción y beneficio. ${ }^{96}$

Esta nueva concepción fue especialmente importante para el sector femenino de la sociedad que fue paulatinamente reemplazando al masculino como servicio doméstico en las casas de importante nivel económico. La naturaleza temporal del trabajo basado en un sueldo conllevó distintas consecuencias para las mujeres que para los hombres, pues su trabajo como criadas se consideraba no solo una forma de ocupación laboral per se (como en el caso de los hombres), sino también un medio para formarse en los conocimientos relativos a la casa que habrían de necesitar como esposas. ${ }^{97}$

Las criadas también se vieron inmersas en la economía de mercado. Dado que con la nueva concepción del trabajo doméstico percibían un sueldo en metálico a cambio de sus servicios, tuvieron que decidir cómo emplear ese dinero, bien en un gasto inmediato o en alguna forma de inversión que protegiera e incrementara los ahorros. Una criada podía

\footnotetext{
91 Fábregas García 2013.

92 Coulon 2001, 729.

93 AHPS. Sección Protocolos. Leg.2158. Fol.107v.

94 Wall 2002, 201-203.

95 Neill 2000, 22.

96 Kussmaul 1981, 8-10.

97 Hanawalt 1986, 145. Barron 1996, 147.
} 
ser capaz de recabar a lo largo de su vida una importante suma de dinero o bienes para su uso personal en el futuro..$^{98}$ Desconocemos el fin de los 6.800 maravedís ganados por Teresa López.

\section{Relaciones familiares y sociales}

Las terceras mantuvieron estrechas relaciones con sus familiares, ${ }^{99}$ lo cual hubiera sido imposible, en principio, en el caso de profesar en alguna Orden como monjas. Esta vinculación presenta distintas formas de manifestación. Relaciones de carácter económico, como los casos de Isabel Sierra que vendió a su hermano su olivar en el Pago de Capirote ${ }^{100}$ por 4.500 maravedís, ${ }^{101}$ y el de doña Brianda de Villavicencio, ${ }^{102}$ viuda $^{103}$ de don Fernán Ruiz Cabeza de Vaca, veinticuatro, que arrendó a un miembro de su familia, Benito Núñez de Villavicencio, también veinticuatro, un donadío de tierras en la Fuente de los Ballesteros. ${ }^{104}$ Los datos biográficos que aporta el documento resultan de un gran interés. Brianda había enviudado y, posiblemente, fue tras la muerte de su marido ${ }^{105}$ cuando ingresó en la Orden Tercera franciscana. En ese mismo año, 1536, documentamos a Brianda de Villavicencio en el Convento de Madre de Dios, pero recibe el calificativo de monja profesa. ${ }^{106}$ En el apartado anterior hemos indicado que este Instituto, como convento femenino, fue una fundación autogenética resultado del ingreso en el mismo de un grupo de beatas franciscanas. Estamos ante uno de esos ejemplos en los que a las beatas se las denomina monjas cuando el acto documental tenía lugar en el edificio conventual, pero realmente pertenecían a la Orden tercera y así se las califica en el desenvolvimiento de actividades personales e individuales. ${ }^{107} \mathrm{Al}$ mismo tiempo el documento pone de manifiesto la convivencia entre terceras y monjas, pues el Convento contaba por esa fecha con una abadesa y una vicaria, y junto a ellas estuvo Brianda de Villavicencio en el acto formal registrado ante notario de la entrega de una dote ${ }^{108}$ de 70.000 maravedís por parte de Ángela de Orellana. Se trataba de una niña de 11 años que a la muerte de su padre quiso ingresar en el Convento de Madre de Dios.

Muy especial debió ser el vínculo entre María Rodríguez y la hija de su sobrino, a quien mandó para su dote, ${ }^{109}$ y por ser commo soys doncella onesta e tenéys pocos bienes, 5.000 maravedís que obtendría del negocio a

\footnotetext{
98 Mcintosh 2005, 49.

99 Pastor de Togneri 2004.

100 Martín Gutiérrez 2004, 140.

101 AMJFPN Alonso Sarmiento. 30 de junio de 1535. Fol.453v.

102 Ruiz Pilares 2012.

103 No es el primer caso de viuda que tras el fallecimiento del marido decidió ingresar en la Orden Tercera Franciscana. En Córdoba contamos con el ejemplo de doña Marina de Aguayo. Véase: Graña Cid 2006, 288-289.

104 AMJFPN Rodrigo de Rus. 2 de mayo de 1536. Fol.370r.

105 La condición de viuda permitía a la mujer medieval gozar de un amplio margen de actuación en muy diversos ámbitos personales y sociales: Pérez González 2010, 35-46.

106 AMJFPN. Luis de Llanos. 1536. Fol.600r.

107 En ocasiones se las denomina Clarisas de la Tercera Regla: Miura Andrades 1998, 251.

108 Pérez Carazo 2008, 105.

109 Sánchez Collada 2016, 717-718.
}

que fuese sometida la casa de la tercera tras su muerte. ${ }^{110}$ Este ejemplo resulta sumamente interesante, puesto que una mujer que había optado por una forma de vida muy distinta de la que la sociedad esperaba de ella (un marido, los hijos, el hogar) contribuyó con su donación a que una sobrina cumpliese con el principal rol asignado al colectivo femenino. ${ }^{111}$

Una categoría diplomática a partir de la cual podemos tener un mayor conocimiento de la implicación social de las terceras son los poderes. En ellos se comisiona a una persona para llevar a cabo una determinada actuación en nombre de quien otorga dicho documento. Pero, dado que el acto principal de este tipo de contrato es precisamente esa comisión autorizada, se omiten otros datos en relación con la misión que se va a cumplir, datos que nos permitirían conocer algunos patrimonios de miembros de las Órdenes Terceras, pero que resulta imposible al prescindirse de detalles que se consideran innecesarios para la concesión del poder.

El ejemplo más claro de cuanto hemos afirmado es el de María Castillo, ${ }^{112}$ que otorgó un poder a Martín Castillo, clérigo, vecino de Alcalá de Guadaira, para que en su nombre cobrase lo que le debían de las rentas de ciertos bienes que ella tenía en dicha localidad. Fuera de toda duda queda el cometido que fray Pedro, fraile profeso del convento de Santa María de la Merced, debía llevar a cabo en nombre de Ana Fernández de Fonseca: ${ }^{113}$ cobrar a Francisco de Ávila 1.000 maravedís que debía a Beatriz de Fonseca, difunta, hija de la citada Ana. Llamamos la atención sobre el hecho de que siendo tercera franciscana no encomiende el cobro a un fraile de su Orden, sino a un mercedario. Quizás la confianza que Ana tenía depositada en fray Pedro era mayor que en otro cualquier hermano franciscano.

\section{El prestigio socio-religioso}

Los miembros de las Órdenes Terceras gozaron de un prestigio importante dentro de la sociedad a la que pertenecían. Estas mujeres optaron por una forma especial de religiosidad con una doble inspiración activa-contemplativa, lo que se traducía en una combinación entre oración y desempeño de funciones englobadas en la cura animorum. Las labores asistenciales, caritativas, hospitalarias y solidarias que desarrollaron fuera de los claustros las revistieron de una consideración especial y las hacían portadoras de unos valores de especial reconocimiento social. ${ }^{114}$ De hecho es una dimensión pastoral, de caridad y de acompañamiento en la acción interna y externa lo que constituye uno de los rasgos más distintivos de la forma de vida que representan las terceras.

Entre las actuaciones más vinculadas a cuestiones de índole religiosa observamos que es en los testamentos y, más en concretamente, en el nombramiento de las terceras como albaceas, donde estas tuvieron un protagonismo más destacado. Su persona, su carácter cuasi sagrado derivado de las bendiciones y consagraciones que habían recibido y

\footnotetext{
110 AMJFPN Rodrigo de Rus. 14 de mayo de 1536. Fol.421r.

111 Leva Cuevas 2008.

112 AHPS Sección Protocolos. Año 1502. Leg.2161. Fol.43r

113 AHPS Sección Protocolos. Leg.1500. Fol.750r.

114 Graña Cid 2006, 291.
} 
realizado al ingresar en los grupos terceros y, creemos que especialmente, una estrecha relación con quien expresaba su última voluntad, convirtieron a algunas terceras en garantes del cumplimiento de una serie de mandas cuyo fin las hacía merecedoras de una atención especial: las honras fúnebres y celebraciones pro remedio animae.

Entre los nombramientos como albaceas testamentarios $^{115}$ documentamos a Ana Sánchez, ${ }^{116}$ que fue designada para el cumplimiento de sus mandas testamentarias por Juana de Casas, honesta. La citada Ana Rodríguez acabó rechazando el cometido por hallarse enferma. Podemos pensar en una vinculación derivada de unas opciones similares de formas de vida cristiana.

\section{CONCLUSIONES}

El estudio de las mujeres pertenecientes a la Orden tercera franciscana no es sencillo debido a su carácter complejo y heterogéneo. Las terceras tenían una condición canónica difícil de precisar, situada entre lo laico y lo eclesiástico, con una adaptación permanente a las diferentes coyunturas. Ello dificulta en extremo la localización de evidencias documentales que permitan establecer con rotundidad tiempos y tipologías.

Las terceras franciscanas representan una de las novedades religiosas más destacadas del periodo bajomedieval. Su vida religiosa se basaba en los ideales que hicieron posibles la promoción espiritual del laicado desde la Baja Edad Media tales como la penitencia, la comunicación directa con Dios y la pobreza. Al mismo tiempo gozaron de un carisma activocontemplativo que las asemejaba a los beaterios en cuanto a un modelo existencial apostólico fuera de la rigidez claustral. Finalmente, su estilo de vida recibió reconocimiento público hasta casi caracterizarse como verdadera profesión, y fueron capaces de ser identificadas como colectivo femenino a nivel social y dentro de su Orden lo que supuso la institucionalización de las terceras.

Sin embargo esa identificación institucional y profesional, favorecida sin duda por la vinculación con el convento franciscano y una clara sintonía institucional con los frailes, no estaba acompañada de una definición terminológica precisa. Los escribanos públicos no tenían una denominación exacta para aplicarla a los miembros femeninos de la Orden tercera. Ni siquiera ellas reclamaron un único nombre que definiera su religiosidad laical, por lo que creemos que ni la sociedad ni las terceras consideraron necesario implementar un proceso de concretización terminológica.

A nivel social las terceras tuvieron un escaso protagonismo en la ciudad como propietarias de distintos bienes, que se limitan a casas y rentas perpetuas. La escasez documental que existe al respecto no creemos que sea resultado de una pérdida de los asientos notariales, sino más bien el resultado del acatamiento de los principios regidores de las Órdenes Mendicantes, que obligaba a una renuncia casi absoluta de todo lo que fuese contrario a una existencia dominada por la austeridad y la pobreza. Por el contrario, ciertas actividades comerciales y financieras visibilizaron a algunas de las terceras como protagonistas importantes e, incluso, poderosos en las redes que articulaban ambos mercados. El comercio de

\footnotetext{
115 García Guzmán y Abellán Pérez 1997, 54.

116 AHPS Sección Protocolos. Año 1504. Leg.17422. Fol.536r.
}

un bien de lujo como el azúcar y los contratos de compras de rentas posibilitaron el acceso de estas mujeres a una esfera eminentemente masculina, que exigía unos certeros conocimientos de sus mecanismos así como de un capital que prestar o invertir según los casos.

Esta forma de vida religiosa fuera del marco institucional tradicional que representaba el convento hizo posible el mantenimiento y alimento de los vínculos familiares y amistosos. Estas relaciones con los miembros de la propia familia discurrieron por cauces tan diversos como los vinculados al mundo de los negocios o a las actividades solidarias ejercidas con otras mujeres del núcleo familiar. En ocasiones los lazos personales se estrecharon sobre la base de la mutua confianza.

Por tanto, las terceras representan una opción personal de vivir la religiosidad cristiana por parte de un grupo de mujeres que decidieron ser dueñas de sus destinos, por lo que renunciaron a toda forma de institucionalización que las pudiese constreñir en su individualizada toma de decisiones. Perfectamente integradas en buena parte de los mecanismos articuladores de la sociedad a la que pertenecían, decidieron vivir la religiosidad cristiana de forma no original, pues estaban impregnadas de todo un movimiento espiritual vigente en la época, pero sí de forma personal y adaptada a su vivir cotidiano en un entorno social al que no estaban dispuestas a renunciar y en el que ejercieron su influencia a través de distintos cauces de implicación.

Cuando los valores que representaban dejaron de ser considerados válidos, pues la jerarquía eclesiástica comenzó tomar medidas en relación a los colectivos de mujeres "sueltas», las terceras, al igual que otros grupos similares, hubieron de elegir dos caminos: la integración en el marco institucional a través de la vía de la clausura en el convento de la Orden segunda franciscana; o continuar con las pautas existenciales por las que había optado, habiendo de sufrir todo tipo de presiones por parte de la jerarquía eclesiástica. La falta de estudios sobre estos grupos durante el Barroco nos impide dilucidar en qué acabaron convirtiéndose o cómo se adaptaron a las nuevas y poco favorables circunstancias para su vivir diario.

\section{BiBLIOGRAFÍA}

Alvarado Planas, Javier y Regina María Pérez Marcos. 2010. «Feudalismo y Derecho feudal». En Historia del Derecho Español, coord. Javier Alvarado Planas, 324-335. Madrid: Universidad Nacional de Educación a Distancia.

Almansa Segura, Rufino. 2003. «El monasterio de San Juan de la Penitencia de Cazorla, de monjas clarisas». En El Franciscanismo en Andalucía, ed. Manuel Peláez del Rosal, 299-308. Córdoba: Cajasur.

Álvarez Fernández, María y Soledad Beltrán Suárez. 2015. Vivienda, gestión y mercado inmobiliario en Oviedo en el tránsito de la Edad Media a la Modernidad. Vitoria: Universidad del País Vasco.

Ashtor, Eliyahu. 1981. "Levantine Sugar Industry in the Late Middle Ages: A Case of Technological Decline». En The Islamic Middle East, 700-1900: Studies in Economic and Social History, ed. Abraham Udovitch, 220-260. Princeton: Darwin Press.

Aznar Vallejo, Eduardo. 1997. "Corso y piratería en las relaciones entre Castilla y Marruecos en la baja Edad Media». En la España Medieval 20: 407-419.

Aznar Vallejo, Eduardo. 2003. «Andalucía y el Atlántico norte a finales de la Edad Media». Historia, Instituciones y Documentos 30: $103-120$. 
Barron, Caroline. 1996. «The Education and Training of Girls in FifteenCentury London». En Courts, Counties and the Capital in the Later Middle Ages, 139-153. New York: Sutton Publishing Company.

Bazán Díaz, Iñaki y Cesar González Mínguez, coord. 2005. El discurso legal ante la muerte durante la Edad Media en el nordeste peninsular. Vitoria: Universidad del País Vasco.

Bejarano Rubio, Amparo. 1990. El hombre y la muerte. Los testamentos murcianos bajomedievales. Cartagena: Ayuntamiento de Cartagena.

Benito Ruano, Eloy. 1970. «Usura y cambios en el León medieval». Archivos Leoneses 47-48: 203-208.

Bermúdez de Pedraza, Francisco. 1608. Antigüedad y excelencias de Granada. Madrid: Por Luis Sánchez, impresor del rey.

Borrero Fernández, Mercedes. 1986. «Efectos del cambio económico en el ámbito rural. Los sistemas de crédito en el campo sevillano (fines del siglo XV y principios del XVI». En la España medieval V: 219-244.

Bisson, Thomas N. 1989. Feudalism in Twelfth Century Catalonia, en Medieval France and her Pyrenean Neighbours. Studies in Early Institutional History. London-Ronceverte: The Hambledon Press.

Bourin, Michel. 2007. "Peasant Elites and Village Communities in the South of France, 1200-1350». Past And Present 2: 101-114.

Cabrera Sánchez, Margarita. 1993. «Oligarquía urbana y negocio inmobiliario en Córdoba en la segunda mitad del siglo XV». Historia, Instituciones y Documentos 20: 107-126.

Carlé, María del Carmen. 1982. "La casa en la Edad media castellana». Cuadernos de Historia de España 67-68: 165-229.

Cedergre, Harry R. 1983. "Sociolingüística». En Introducción a la lingüística actual, coord. Humberto López Morales. Madrid: Playor.

Clavero Salvador, Bartolomé. 1977. «Prohibición de la usura y constitución de rentas». Moneda y crédito: 107-131.

Clavero Salvador, Bartolomé. 1979. «Interesse: traducción e incidencia de un concepto en la Castilla del siglo XVI». Anuario de historia del derecho español 49: 39-98.

Collantes de Terán Sánchez, Antonio. 1988. «Propiedad y mercado inmobiliario en la Edad Media: Sevilla, siglos XIII-XVI». Hispania 169: 493-528.

Collantes de Terán Sánchez, Antonio. 2007a. «El modelo meridional, Sevilla». En Mercado inmobiliario y paisajes urbanos en el Occidente europeo (siglos XI-XV), 591-630. Pamplona: Gobierno de Navarra.

Collantes de Terán Sánchez, Antonio. 2007b. «Los centros urbanos andaluces de la frontera con Granada». En Jornadas de Historia de Lucena, 41-66. Lucena: Excelentísimo Ayuntamiento.

Colombo, Octavio. 2016. «Los dueños del dinero. Prestamistas abulenses a mediados del siglo XV». Espacio, tiempo y Forma. Historia Medieval 29: 249-277. http://doi.org/10.5944/etfiii.29.2016

Coulon, Damien. 2001. «El comercio catalán del azúcar en el siglo XIV». Anuario de Estudios Medievales 31 (2): 729-756. https://doi. org/10.3989/aem.2001.v31.i2.267

De Almeida Costa, Mario Joao. 1961. Raizes do censo consignativo. Para la historia do crédito medieval portugués. Coimbra: Atlántica.

Fábregas García, Adela. 2013. «El azúcar en los mercados europeos a fines de la Edad Media. El ejemplo del azúcar nazarí». En El sucre en la historia: alimentació, quotidianitat i economía, coord. Flocel Sabaté y Currull, 147-160. Lleida: Ajuntament de Menàrguens.

García de Valdeavellano, Luis. 1973. «El “Renovo”: notas y documentos sobre los préstamos usurarios en el reino astur-leonés (siglos X-XI)». Cuadernos de Historia de España 57-58: 408-448.

García Guzmán, María del Mar y Juan Abellán Pérez. 1997. La religiosidad de los jerezanos según sus testamentos (siglo XV). Cádiz: Agrija Ediciones.

Graña Cid, María del Mar. 1993. «Las primeras clarisas andaluzas: franciscanismo femenino y reconquista en el siglo XIII». Archivo Ibero-Americanos 215-216: 661-704.

Graña Cid, María del Mar. 1997. «Franciscanos y franciscanas en el reino de Granada. Panorama fundacional (ca. 1485-1550)». En El Franciscanismo en Andalucía, ed. Manuel Peláez del Rosal, 105119. Córdoba: Cajasur.
Graña Cid, María del Mar. 2002a. «En torno a la fenomenología de las santas vivas (Algunos ejemplos andaluces, siglos XV-XVI)». En Responsabilidad y diálogo. Homenaje a José Joaquín Alemany Briz, SJ (1937-2001), ed. Xavier Quinzá Lleó y Gabino Uríbarri Bilbao, 415-454. Madrid: Universidad Pontificia Comillas.

Graña Cid, María del Mar. 2002b. «La santa/bruja Magdalena de la Cruz. Identidades religiosas y poder femenino en la Andalucía pretridentina». En Actas del III Congreso de Historia de Andalucía, 103-120. Córdoba: Universidad de Córdoba.

Graña Cid, María del Mar. 2006. «Las terciarias franciscanas en la pugna conventuales /observantes. Jurisdicción religiosa y problemas de género». En Los Franciscanos Conventuales en España. Actas del III Congreso Internacional sobre el Franciscanismo en la Península Ibérica, coord. Gonzalo Fernández-Gallardo Jiménez, 283-294. Priego de Córdoba: Asociación Hispánica de Estudios Franciscanos.

Graña Cid, María del Mar. 2011. «Autoría femenina y carisma religioso. Orígenes de las clarisas descalzas en Andalucía». En Historia magistra vitae. Miscelánea de estudios en homenaje a Tarsicio de Azcona, ed. José Ángel Echeverría. Pamplona: Hermanos Menores Capuchinos.

Hanawalt, Barbara. 1986. Women and Work in Preindustrial Europe. Bloomington: Indiana University.

Kussmaul, Adolf. 1981. Servants in Husbandry in Early Modern England. Cambridge: University Press.

Lemire, Beverly. 2001. The business of everyday life. Gender, practice and social politics in England. Manchester: University Press.

Leva Cuevas, Josefa. 2008. «El papel de la mujer en la Edad Media. La dote ¿impulsora del nuevo hogar o yugo para las mujeres». Ámbitos: Revista de Estudios de Ciencias Sociales y Humanidades 19: 69-90.

Martín Gutiérrez, Emilio. 2004. La organización del paisaje rural durante la Baja Edad Media. El ejemplo de Jerez de la Frontera. Sevilla: Universidad de Sevilla.

Mcintosh, Majori Keniston. 2005. Working Women in English society, 1300-1620. Cambridge: University Press.

Meersseman, Gilles Gerard. 1961. Dossier de I'ordre de la penitence au XIIle siècle. Spicilegium Fruburgense, 7. Friburg: Editions Universitaires.

Meersseman, Gilles Gerard. 1977. Ordo Fraternitatis. Confraternite e pietá dei laici nel Medioevo. II. Roma: Herder Editrice e Librería.

Mesa Xinete, Francisco. 1888. Historia sagrada y política de la muy noble y muy leal ciudad de Jerez de la Frontera. Jerez: Imprenta de Melchor García Ruiz.

Miura Andrades, José María. 1992. Fundaciones religiosas y milagros en Écija a fines de la Edad Media. Écija: Gráficas Sol.

Miura Andrades, José María. 1994. «Las fundaciones de clarisas en Andalucía del siglo XIII a 1525». En Las clarisas en España y Portugal, Actas del Congreso Internacional, coord. José Martí Mayor y María del Mar Graña Cid, 705-721. T. II, vol. II. Salamanca: Junta de Castilla y León.

Miura Andrades, José María. 1998. Frailes, monjas y conventos. Las Órdenes mendicantes y la sociedad sevillana bajomedieval. Sevilla: Diputación Provincial.

Miura Andrades, José María. 2014. Monjes, frailes, monjas y otras formas de vida religiosa en Jerez de la Frontera a fines de la Edad Media». En 750 aniversario de la incorporación de Jerez a la Corona de Castilla: 1264-2014, 559-575. Jerez de la Frontera: Ayuntamiento.

Monguio Becher, Fernando. 1978. Antecedentes de la banca en Jerez de la Frontera. Cádiz: CSIC.

Muldrew, Craig. 1998. The Economy of Obligation: The Culture of Credit and Social. New York: St. Martin's Press.

Neill, Michael. 2000 Putting History to the question: Power, Politics, and Society in English Renaissance Drama. New York: Columbia University.

Nelson, Benjamin. 1969. The Idea of Usury. From Tribal Brotherhood to Universal Otherhood. Chicago: University of Chicago.

Pastor de Togneri, Reina. 2004. «Mujeres en los linajes y en las familias: las madres, las nodrizas, mujeres estériles. Funciones, espacios, representaciones». En Mujeres, familia y linaje en la Edad Media, coord. Carmen Trillo San José, 31-68. Granada: Universidad de Granada. 
Pellicia, Guerrino y Giancarlo Rocca, eds. 1992. Dizionario degli Instituti di Perfezione. cc. 1042-1050. T. 6. Roma: Edizioni Paoline.

Pérez Carazo, Pedro. 2008. Santa María de Herce y su abadengo en la Edad Media. Logroño: Instituto de Estudios Riojanos.

Pérez González, Silvia María. 2005. Las mujeres en la Sevilla de finales de la Edad Media. Solteras, casadas y vírgenes consagradas. Sevilla: Servicio de Publicaciones de la Universidad de Sevilla.

Pérez González, Silvia María. 2010. «Mujeres liberadas de tutela masculina: de solteras y viudas a fines de la Edad Media». Cuadernos Kóre 2: 31-54.

Pérez González, Silvia María. 2016. «Nuevas aportaciones al estudio de la cofradías y hermandades en la Castilla bajomedieval: El ejemplo de Jerez de la Frontera». Hispania Sacra 138: 502-520. https://doi. org/10.3989/hs.2016.032

Rubio, Germán. 1953. La custodia franciscana de Sevilla. Ensayo histórico sobre sus orígenes, progresos y vicisitudes (1220-1499). Sevilla: San Antonio.

Ruiz Pilares, Enrique. 2012. "El mayorazgo del veinticuatro Pedro Camacho de Villavicencio 'el rico' (1507). El patrimonio del caballero jerezano más acaudalado de su tiempo». En la España Medieval 35: 317-347.

Sánchez Collada, Teresa. 2016. «La dote matrimonial en el Derecho castellano de la Baja Edad Media. Los protocolos notariales del
Archivo Histórico Provincial de Cuenca (1504-1507)». Espacio, Tiempo y Forma. Serie III. Historia Medieval 29: 699-734.

Sánchez García, Francisco José. 2009. El léxico religioso en los diccionarios de la Real Academia Española: estudio diacrónico. Barcelona: Publicacions i Edicions Universitat de Barcelona.

Sancho de Sopranis, Hipólito y Juan Lastra y Terry. 1964. Historia de Jerez de la Frontera. T. II. Jerez: Editorial Jerez Industrial.

Serrano Estrella, Felipe. 2008. Órdenes mendicantes y ciudad. El patrimonio conventual de Jaén en la Edad Moderna. Granada: Universidad de Granada.

Sevillano Colom, Francesc. 1970. "Mallorca y Castilla (1276-1343)». Boletín de la Sociedad Castellonense de Cultura 46: 321-366.

Tittler, Robert. 1994. "Money-Lending in the West Midlands». Historical Research 164: 249-263.

Torres, Alonso. 1683. Chrónica de la Santa Provincia de Granada, de su regular observancia de nuestro seráfico Padre San Francisco. Madrid: Por Juan García Infanzón, impresor de libros.

Valdivieso González, Enrique y Alfredo José Morales Martínez. 1991. Sevilla oculta: Monasterios y conventos de clausura. Sevilla: Francisco Arenas Peñuela.

Wall, Wendy. 2002. Staging, Domesticity: Household, Work and English Identity in Early Modern Drama. Cambridge: University Press. 